\title{
EPIDEMIOLOGIA GLOBAL DE PACIENTES COM TUBERCULOSE MULTIDROGARRESISTENTE (MDR-TB) E EXTENSIVAMENTE RESISTENTE (XDR-TB)
}

\author{
GLOBAL EPIDEMIOLOGY OF PATIENTS WITH MULTIDRUG- \\ RESISTANT TUBERCULOSIS (MDR-TB) AND EXTENSIVELY \\ DRUG-RESISTANT TUBERCULOSIS (XDR-TB)
}

\author{
Jorge Del Arco Junior ${ }^{1}$, Naiara Cristina Ule Belotti ${ }^{1}$, \\ Naidy Konno Madela1 ${ }^{1}$, Rosângela Siqueira Oliveira², \\ Heloisa da Silveira Paro Pedro ${ }^{1}$
}

\begin{abstract}
RESUMO
A tuberculose multidrogarresistente (MDR-TB) e a tuberculose extensivamente resistente (XDR-TB), levantam preocupações pelo grande número de casos, especialmente na África, Ásia e Europa, e pela taxa de sucesso ainda baixa no tratamento, atingindo $54 \%$ para MDR-TB e $30 \%$ para XDR-TB. O objetivo do presente estudo é relatar as diferentes realidades epidemiológicas dos doentes com MDR-TB e XDR-TB em diferentes partes do mundo. Foram revisados artigos da última década nas bases científicas disponíveis. Os estudos mostraram que a maioria das pessoas afetadas pela MDR-TB são do sexo masculino, migrantes ou imigrantes, que já haviam sido tratados anteriormente. Descrevemos que o tratamento da tuberculose (TB) usualmente resulta em cura, mas também pode levar à seleção dos bacilos mais resistentes. Mostramos que o surgimento de cepas resistentes na TB se deve ao tratamento inadequado de formas mais simples de TB, com cepas resultantes de manejo difícil e que as populações vulneráveis são as mais afetadas. Salientamos que o abandono do tratamento é fator que comumente origina esse problema complexo da doença e elencamos os genes de resistência mais estudados.
\end{abstract}

Palavras-chave: Tuberculose; antibióticos antituberculose; epidemiologia; resistência microbiana a medicamentos; resistência a múltiplos medicamentos; genes MDR

\begin{abstract}
Multidrug-resistant tuberculosis (MDR-TB) and extensively drug-resistant tuberculosis (XDR-TB) raise concerns for their great number of cases, especially in Africa, Asia and Europe, and for their still low treatment success rate, reaching $54 \%$ for MDR-TB and $30 \%$ for XDR-TB. The objective of this study is to report the epidemiological situation of patients with MDR-TB and XDR-TB in different parts of the world. Articles published in the last decade were collected from available scientific databases and reviewed. The studies showed that most of those affected by MDR-TB are male, migrants or immigrants, and had been previously treated for tuberculosis (TB). We report that TB treatment usually ends in cure, but may also lead to selection of the most resistant bacilli. We show that the emergence of resistant strains in TB is due to inappropriate treatment of simpler forms of TB, resulting in strains of difficult management, and that the most vulnerable populations are the most affected. We emphasize that treatment dropout is the factor most commonly associated with this complicated issue, and also list the most studied multidrug resistance genes.
\end{abstract}

Keywords: Tuberculosis; antibiotics antitubercular; epidemiology; drug resistance, microbial; drug resistance, multiple; genes MDR

A tuberculose (TB) é uma doença infecciosa, causada pelo bacilo Mycobacterium tuberculosis (MTB) e considerada um problema de saúde pública global. Está classificada como uma das 10 maiores causa mortis no
Clin Biomed Res. 2018;38(3):281-291

1 Instituto Adolfo Lutz, Centro de Laboratório Regional de São José do Rio Preto. São José do Rio Preto, SP, Brasil.

2 Instituto Adolfo Lutz Central, Núcleo de Tuberculose e Micobacterioses. São Paulo, SP, Brasil.

Autor correspondente: Heloisa da Silveira Paro Pedro heloisa.pedro@ial.sp.gov.br Instituto Adolfo Lutz, Centro de Laboratório Regional de São José do Rio Preto

Rua Alberto Suffredini, 2325. 15060-020, São José do Rio Preto, SP, Brasil. 
mundo. Sem o tratamento apropriado, a mortalidade da TB, cujas estimativas foram de 1,3 milhões para HIV-negativos e 374.000 para HIV-positivos em 2016 , é, em média, de $45 \%$ e quase $100 \%$, respectivamente. Paradoxalmente, com um diagnóstico rápido e tratamento correto, a maior parte dos doentes de TB podem ser curados ${ }^{1,2}$.

Atualmente, o tratamento básico para casos novos de todas as formas de TB, pulmonar e extrapulmonar (exceto meningoencefalite), infectados ou não pelo HIV, consiste em uma associação de fármacos chamados de primeira linha. Este tratamento é dividido em duas fases: a primeira, chamada de fase intensiva, tem duração de dois meses e utilizam-se quatro fármacos: rifampicina, isoniazida, pirazinamida e etambutol. A segunda fase tem duração de quatro meses e é chamada de fase de manutenção, e nesta, somente dois fármacos são utilizados, a rifampicina e a isoniazida ${ }^{3,4}$.

A resistência aos fármacos utilizados no esquema básico de tratamento, especificamente à rifampicina e isoniazida, caracteriza a forma resistente da TB denominada multidroga resistente (MDR-TB). Apesar de haver algumas limitações de detecção de cepas MDR em alguns lugares do mundo, como falta de infraestrutura, estima-se que haja 500 mil novos casos de MDR-TB por ano no mundo, sendo que, $60 \%$ são de novos casos de resistência e $40 \%$ de pacientes previamente tratados. Os países mais afetados por cepas resistentes são as antigas Repúblicas Soviéticas, Índia, China, África do Sul e Bangladesh, com China e Índia contendo mais de $50 \%$ dos casos. Os sintomas da MDR-TB são iguais aos da TB clássica, o que dificulta o diagnóstico em locais onde há dificuldades para detecção do MTB e tratamento da doença, como falta de recursos do sistema de saúde e estigma social em relação à TB ${ }^{5}$.

Além da MDR-TB, também há a TB extensivamente resistente (XDR-TB). Essa forma é caracterizada pela resistência à rifampicina, isoniazida, a qualquer uma das fluoroquinolonas e, pelo menos, a um dos três fármacos injetáveis de segunda linha, sendo estes a amicacina, a canamicina e a capreomicina. A XDR-TB foi descrita em 2006 pelo Centro de Controle de Doenças dos Estados Unidos (CDC) e também pela Organização Mundial da Saúde (OMS) como uma grave ameaça à saúde pública e ao controle da TB e atualmente as informações são escassas. Dados sugerem que $9,7 \%$ dos casos de MDR-TB também são XDR-TB, sendo as maiores proporções de casos XDR-TB para MDR-TB na Bielorrússia, com $29 \%$, e na Lituânia, com $25 \%{ }^{6-8}$.

Quanto ao diagnóstico da TB pulmonar, avanços significativos ocorreram nos últimos anos, tais como as culturas líquidas manuais e automatizadas que ajudaram a diminuir o tempo de detecção do MTB e do teste de sensibilidade aos fármacos. O desenvolvimento e padronização de testes utilizando métodos de biologia molecular levaram à rápida identificação de microbactérias diretamente em amostras clínicas, além de detectar mutações pontuais em genes específicos, que conferem resistência ao bacilo. Estas abordagens possibilitaram melhorar e dar celeridade ao diagnóstico da tuberculose MDR-TB ${ }^{9}$.

Pacientes com TB na forma ativa podem infectar 10 a 15 outras pessoas por meio de contato próximo no período de um $a \mathrm{no}^{2}$, podendo transmitir as formas resistentes, sendo essa considerada como resistência primária, enquanto que a resistência adquirida ao longo do tratamento é referida como resistência secundária ${ }^{6}$.

Visto que a TB é ainda hoje um problema de saúde pública em todo o mundo, e que apresenta uma preocupação crescente nos últimos anos em relação à MDR-TB e à XDR-TB, o presente estudo tem como objetivo abordar aspectos epidemiológicos da tuberculose resistente aos fármacos.

\section{MÉTODOS}

Trata-se de um estudo de revisão bibliográfica que foi utilizado as seguintes bases de dados: Medical Literature Analysis and Retrieval System On-line (MEDLINE), Pubmed, Literatura Latino-Americana e de Caribe em Ciências da Saúde (LILACS), Scientific Electronic Library Online (SciELO), Sistema de Informação da Biblioteca da Organização Mundial de Saúde (WHOLIS), e Google Acadêmico. Os descritores pesquisados foram: Mycobacterium tuberculosis, tuberculose multidrogarresistente, MDR-TB, tuberculose extensivamente resistente, XDR-TB, epidemiologia de tuberculose resistente, epidemiologia da MDR-TB, epidemiologia da XDR-TB, genes de resistência, de forma isolada ou combinada entre si. A pesquisa destes descritores foi realizada no período de setembro a novembro de 2017 e resultou em 96 estudos. Após uma avaliação crítica dos títulos, resumos e leitura completa dos textos foram excluídos 51 estudos e mantidos 45 artigos completos dos quais foram discutidos e considerados como literaturas pertinentes nesta revisão.

\section{TUBERCULOSE MULTIDROGA RESISTENTE (MDR-TB)}

Em 1943 foi isolado o primeiro agente antituberculose, a estreptomicina, e no ano seguinte, o primeiro paciente foi declarado curado da TB, seguido de outros pacientes tratados com êxito. Em 1951, a isoniazida foi testada e, melhorando dramaticamente o prognóstico dos pacientes, foi logo distribuída para 
amplo uso. Nos anos seguintes, foram introduzidos fármacos que são utilizados até hoje no tratamento da TB, como a pirazinamida (1952), a rifampicina (1957) e o etambutol (1962). Mas para cada advento de um novo fármaco, encontravam-se eventos de seleção de mutações que conferiam ao bacilo uma nova resistência, especialmente em pacientes que utilizavam apenas um fármaco, sendo necessária então a criação de um esquema de tratamento com uso combinado de vários fármacos, que é usado até hoje para o tratamento da $\mathrm{TB}^{10}$.

O uso inapropriado ou incorreto dos fármacos, ou formulações ineficazes, tais como a monoterapia, fármacos de má qualidade ou más condições de armazenamento, além da prematura interrupção do tratamento podem levar à resistência do bacilo, que então pode ser transmitido, especialmente em ambientes superlotados, como prisões e hospitais. Apesar disso, após o início do tratamento para a MDR-TB, os pacientes perdem a capacidade de transmitir a doença $a^{11,12}$.

A detecção da resistência em cepas do MTB pode ser feita de maneira clássica, utilizando os testes baseados na cultura do bacilo, como o método das proporções. Embora confiável este teste possui uma grande desvantagem: o tempo de 4 a 6 semanas de incubação para um resultado fidedigno. Os métodos de cultura líquida, lançado nos anos 1980, sendo este o BACTEC MGIT960 (Becton Dickinson, Sparks, $M D, E U A)$, são bem mais rápidos detectando a resistência em 5 a 9 dias ${ }^{13}$.

Entre os métodos moleculares, destacam-se três testes comerciais: o INNO-LiPA Rif. TB (Innogenetics, Zwijndrecht, Bélgica), que detecta a resistência à rifampicina; o Genotype MTBDR plus (Hain LifeScience $\mathrm{GmbH}$, Nehren, Alemanha), que diagnostica cepas resistentes à rifampicina e isoniazida; e o GeneXpert MTB/RIF (Cepheid, Sunnyvale, CA, EUA), que identifica a resistência à rifampicina. Esses testes baseiam-se na detecção de mutações no gene rpo $B$, que codifica a RNA polimerase bacteriana, inhA, que codifica a enoyl-acyl proteína redutase, e $k a t G$, que codifica as enzimas catalase e peroxidase ${ }^{14}$.

Os fármacos a serem utilizados no tratamento da MDR-TB dependem dos resultados dos testes de sensibilidade e devem ser escolhidos por um especialista que acompanha o paciente. Para adultos, o esquema inicial de tratamento deve conter ao menos quatro drogas ativas na fase intensiva e três na fase de manutenção, que devem ser escolhidas de acordo com a existência ou não de resistência da cepa isolada do paciente àquele fármaco. Os medicamentos utilizados estão dispostos na tabela $1^{15,16}$.

A Organização Mundial de Saúde ${ }^{15}$ diz que um regime mais curto de tratamento, de 9 a 12 meses, pode ser utilizado para pacientes que não foram tratados com fármacos injetáveis de segunda linha e também
Tabela 1: Fármacos utilizados no tratamento de resistência à TB.

\begin{tabular}{|c|c|c|}
\hline \multicolumn{3}{|c|}{ Fluoroquinolonas de $2^{\mathrm{a}}$ linha } \\
\hline \multicolumn{3}{|c|}{ Levofloxacina } \\
\hline \multicolumn{3}{|c|}{ Moxifloxacina } \\
\hline \multicolumn{3}{|c|}{ Gatifloxacina } \\
\hline \multicolumn{3}{|c|}{ Fármacos injetáveis de segunda linha } \\
\hline \multicolumn{3}{|c|}{ Amicacina } \\
\hline \multicolumn{3}{|c|}{ Capreomicina } \\
\hline \multicolumn{3}{|c|}{ Canamicina } \\
\hline \multicolumn{3}{|c|}{ Outros importantes Fármacos de segunda linha } \\
\hline \multicolumn{3}{|c|}{ Etionamida/Protionamida } \\
\hline \multicolumn{3}{|c|}{ Linezolida } \\
\hline \multicolumn{3}{|c|}{ Clofazimina } \\
\hline \multicolumn{3}{|c|}{ Fármacos adicionais } \\
\hline Grupo 1: & Grupo 2: & Grupo 3: \\
\hline Pirazinamida & Bedaquilina & $\begin{array}{c}\text { Ácido } \\
\text { 4-aminossalicílico }\end{array}$ \\
\hline Etambutol & Delamanida & $\begin{array}{l}\text { Imipenem- } \\
\text { Cilastatina }\end{array}$ \\
\hline \multirow{2}{*}{$\begin{array}{l}\text { Alta dose de } \\
\text { Isoniazida }\end{array}$} & & Meropenem \\
\hline & & $\begin{array}{l}\text { Amoxicilina/ } \\
\text { Ácido } \\
\text { Clavulânico }\end{array}$ \\
\hline
\end{tabular}

Fonte: World Health Organization ${ }^{15}$.

para os que não estejam infectados com cepas que apresentaram resistência às fluoroquinolonas. Para outros pacientes que apresentam algum desses tipos de cepas resistentes, a duração do esquema de tratamento deve levar em conta alguns fatores, tais como a combinação considerada efetiva, o equilíbrio entre o benefício do tratamento e seus efeitos colaterais e a resposta ao tratamento individual do paciente ${ }^{15}$.

\section{TUBERCULOSE EXTENSIVAMENTE RESISTENTE (XDR-TB)}

A XDR-TB é definida como a MDR-TB, ou seja, resistência à rifampicina e à isoniazida, acrescida da resistência a qualquer uma das fluoroquinolonas e pelo menos um dos fármacos injetáveis de segunda linha. Tal definição demonstra o pobre prognóstico dos acometidos pela XDR-TB, visto que a amicacina, a capreomicina e a canamicina são fármacos muito mais eficazes no tratamento do que, por exemplo, a cicloserina e o ácido 4-aminossalicílico. Essa forma de TB ganhou destaque quando, em 2005, ocorreu uma grande epidemia num hospital de Kwazulu Natal, na África do Sul, em que muitos pacientes contraíram a XDR-TB, incluindo pacientes soropositivos para HIV, e morreram dias após a infecção por terem sido tratados para TB normal ${ }^{17}$. 
A chance de sucesso do tratamento da TB diminui, quanto mais resistente for o bacilo. Nas cepas sensíveis, as taxas de sucesso são entre $70 \%$ e $95 \%$, na XDR-TB, fica entre $20 \%$ e $50 \%$. Um fator importante ligado ao sucesso é a resistência aos fármacos adicionais de primeira e segunda linha, além dos já definidos nas classificações de MDR-TB e XDR-TB ${ }^{18}$.

\section{MECANISMOS DE RESISTÊNCIA DO MTB}

Resistência do MTB geralmente são resultados de mutações pontuais, inserções ou deleções de fragmentos curtos, ou mais raramente, deleções longas ${ }^{6}$.

O mecanismo mais comum de resistência é a mutação que ocorre no gene que codifica o alvo do fármaco (usualmente uma enzima), cuja inibição resulta na atenuação da sua capacidade de se ligar ao alvo. Também são causas de resistência: mutações que aumentam a expressão da proteína alvo, diminuição quantitativa do fármaco dentro da célula e pela modificação química da proteína que inativa o fármaco. A demora no diagnóstico da resistência e o consequente atraso na escolha do melhor esquema terapêutico contribuem para o aumento dos índices de MDR-TB ${ }^{19}$.

Podem ser definidos quatro tipos de resistência: a natural, que ocorre de forma espontânea na natureza, sem que o $M$. tuberculosis tenha tido contato com nenhum fármaco; a inicial, detectada quando o paciente se apresenta para o tratamento, podendo ser a um ou mais fármacos e inclui pacientes sobre os quais não há conhecimento de tratamentos prévios; a primária, onde o paciente sabidamente não realizou tratamentos anteriores e foi infectado por um bacilo resistente; e a adquirida ou secundária, consequência de tratamentos prévios mal realizados ${ }^{20}$.

A tabela 2 elenca os principais genes de resistência afetados por mutações, os fármacos envolvidos, as atividades funcionais dos genes e os mecanismos de resistência aos fármacos.

Tabela 2: Relação de genes modificados, fármacos envolvidos, atividades funcionais dos genes, tipos de alterações genéticas ocorridas e resultados das alterações.

\begin{tabular}{|c|c|c|c|c|}
\hline Genes modificados & Fármaco & Atividade funcional do gene & $\begin{array}{l}\text { Tipo de } \\
\text { alteração } \\
\text { genética }\end{array}$ & $\begin{array}{l}\text { Consequência da } \\
\text { alteração genética }\end{array}$ \\
\hline$r p o B$ & Rifampicina & $\begin{array}{c}\text { Subunidade } \beta \text { da RNA } \\
\text { polimerase }\end{array}$ & Mutação & $\begin{array}{l}\text { Impede a interação do } \\
\text { fármaco com a enzima }\end{array}$ \\
\hline pncA & Pirazinamida & $\begin{array}{c}\text { Ativa a enzima } \\
\text { Pirazinamidase e transforma } \\
\text { a pirazinamida em ácido } \\
\text { pirazinoico }\end{array}$ & Mutação & $\begin{array}{l}\text { Diminuição na produção } \\
\text { do ácido pirazinóico, } \\
\text { metabólito ativo da } \\
\text { Pirazinamida }\end{array}$ \\
\hline$r p s L$ & Estreptomicina & subunidade ribossomal S12 & Mutação & $\begin{array}{c}\text { Impede a interação com a } \\
\text { estreptomicina }\end{array}$ \\
\hline katG & Isonoazida & Catalase-peroxidase & Mutação & $\begin{array}{c}\text { Impede a ativação do } \\
\text { Fármaco }\end{array}$ \\
\hline $\operatorname{inh} A$ & Isoniazida & Enoil-ACP redutase & $\begin{array}{l}\text { Mutações } \\
\text { que levam ao } \\
\text { aumento da } \\
\text { expressão }\end{array}$ & $\begin{array}{c}\text { Níveis elevados da enzima } \\
\text { superam o poder inibitório } \\
\text { da isoniazida }\end{array}$ \\
\hline embABC & Etambutol & Arabinosil transferase & $\begin{array}{l}\text { Mutação ou } \\
\text { aumento da } \\
\text { expressão }\end{array}$ & $\begin{array}{c}\text { Permite a síntese contínua } \\
\text { de arabinogalactanos } \\
\text { (relacionado ao etambutol) }\end{array}$ \\
\hline rrs & Estreptomicina & RNA ribossomal $16 \mathrm{~S}$ & Mutação & $\begin{array}{c}\text { Impede interação com a } \\
\text { estreptomicina }\end{array}$ \\
\hline tlyA & Capreomicina & $\begin{array}{l}\text { Codifica a rRNA } \\
\text { metiltransferase }\end{array}$ & Mutação & $\begin{array}{l}\text { Modificação de dois } \\
\text { nucleotídeos que conferem } \\
\text { resistência cruzada entre } \\
\text { amicacina, kanamicina e } \\
\text { capreomicina }\end{array}$ \\
\hline $\begin{array}{l}\text { gyrA } \\
\text { gyrB }\end{array}$ & Fluoroquinolona & $\begin{array}{c}\text { Inibem atividade da enzima } \\
\text { DNA girase ou topoisomerase } \\
\text { II e topoisomerase IV } \\
\text { bacteriana }\end{array}$ & Mutação & $\begin{array}{l}\text { Inibe replicação do } \\
\text { DNA } \\
\text { e crescimento } \\
\text { bacteriano }\end{array}$ \\
\hline
\end{tabular}

Fonte: Santos et al. ${ }^{20}$; Zhang e Yew ${ }^{21}$; Zhang e Yew ${ }^{22}$; Almeida Da Silva e Palomino ${ }^{23}$. 


\section{CARACTERÍSTICAS EPIDEMIOLÓGICAS DE PACIENTESCOM MDR-TB E XDR-TB EM DIFERENTES CONTINENTES}

\section{Continente Africano}

Em 2016, 19,67\% dos casos de TB notificados no mundo, foram no continente africano ( 1.303 .483 casos). Dentre esses, 27.828 foram casos de MDR-TB ou casos de TB rifampicina resistente (RR-TB), e 1.092 casos de XDR-TB. Quanto ao sucesso do tratamento, o continente africano fica em $2^{\circ}$ lugar no mundo, com destaque para Somália, República Democrática do Congo e Nigéria, cujas taxas de sucesso no tratamento foram maiores que no restante do continente ${ }^{1,24}$.

Em um estudo realizado nos países da Comunidade do Leste Africano, uma união de livre comércio composta por Burundi, Quênia, Ruanda, Tanzânia e Uganda, foi descrito que os maiores fatores de risco para o surgimento da MDR-TB foram: casos recorrentes de TB, em que a resistência a qualquer fármaco era de até $30 \%$; soropositividade para HIV e em casos de refugiados, devido à alta concentração populacional e desorganização dos serviços de saúde em campos de refugiados ${ }^{25}$.

Outro fator crítico são os imigrantes advindos de países sem um programa de combate à TB. Em Camarões, onde existe o Programa Nacional de TB, pacientes receberam de 2008 a 2012, um tratamento padronizado de 12 meses, que apresentou uma taxa de sucesso terapêutico de $89 \%$. Desde
2013, foi adotado um novo regime, de nove meses, com taxa de sucesso de $82 \%$. Muitos pacientes da Guiné Equatorial foram para Camarões em busca de tratamento, e foram tratados como se a realidade epidemiológica de seu país fosse igual à de Camarões. Entretanto, dois casos recentes de pacientes provenientes da Guiné Equatorial apresentaram resistência às fluoroquinolonas, fato até então inédito em Camarões. A "invasão" de pacientes infectados com isolados de diferentes perfis de resistência diminui a eficácia de programas de combate à TB. Este fator é muito preocupante devido à disseminação de cepas resistentes diferentes do perfil epidemiológico de Camarões, dificultando o diagnóstico correto, uma vez que o programa do país não atende a epidemiologia dos países vizinhos ${ }^{26}$.

\section{Continente Americano}

O continente americano apresentou o menor número de casos de TB entre as regiões estudadas no ano de 2016 . Foram 233.793 casos notificados, representando apenas $3,52 \%$ do total mundial. As formas resistentes são também os menores registros no mundo (Tabela 3). Entretanto, as Américas possuem o pior índice de sucesso terapêutico para o tratamento da $\mathrm{MDR} / \mathrm{RR}$-TB entre as regiões estudadas, com apenas $46 \%$ dos pacientes com tratamento bem sucedido. Entre 30 países que tem alto índice de MDR/RR-TB, o Peru foi o que apresentou o pior índice de sucesso terapêutico, com apenas $34 \%^{1,24}$.

Tabela 3: Casos confirmados, freqüência de sucesso do tratamento e principais dados epidemiológicos de MDR/RR-TB e XDR-TB de pacientes com resistência em diferentes regiões do mundo.

\begin{tabular}{cccccc}
\hline Região & $\begin{array}{c}\text { Casos } \\
\text { confirmados } \\
\text { de MDR/ } \\
\text { RR-TBn }\end{array}$ & $\begin{array}{c}\text { Frequência } \\
\text { de Sucesso } \\
\text { do tratamento } \\
\text { \% }\end{array}$ & $\begin{array}{c}\text { Casos } \\
\text { confirmados } \\
\text { de XDR-TBn }\end{array}$ & $\begin{array}{c}\text { Frequência de } \\
\text { Sucesso do } \\
\text { tratamento } \\
\%\end{array}$ & $\begin{array}{c}\text { Principais características } \\
\text { epidemiológicas (Referência, Ano) }\end{array}$ \\
\hline $\begin{array}{c}\text { África } \\
\text { Américas }\end{array}$ & $\begin{array}{c}27.828 \\
3.715\end{array}$ & 59 & 1.092 & 27 & HIV+; refugiados; casos recorrentes de TB ${ }^{25}$ \\
Tabagismo; falha terapêutica; gênero \\
$\begin{array}{c}\text { Mediterrâneo } \\
\text { oriental }\end{array}$
\end{tabular}


Em estudo realizado no estado do Espírito Santo, no Brasil, foram observados os maiores fatores de risco para o aparecimento da TB resistente, sendo eles, o histórico de tratamento para a TB e o recomeço após abandono, tabagismo, e a cultura positiva para o MTB no momento da notificação. O histórico de tratamento somado ao recomeço de tratamento após abandono leva à resistência devido ao aumento do contato da micobactéria com a droga, causando uma pressão de seleção das micobactérias mais resistentes aos fármacos. O tabagismo normalmente é associado à falha terapêutica no tratamento da TB, também pode causar um aumento do tempo para a negativação da baciloscopia, além de tabagistas terem 2,5 mais chances de terem TB recorrente, daí justifica-se o surgimento de cepas resistentes ${ }^{27}$.

No Brasil, o número de casos de MDR-TB era de 334 em 2001, contra 702 em 2014, demonstrando um crescimento expressivo no período. É importante salientar que na parte final desse período o Programa Nacional de Tuberculose passou a priorizar a realização de testes de sensibilidade e cultura para casos de reinício de tratamento e em populações vulneráveis. Já a XDR-TB é altamente subnotificada, e tal forma demonstra a falha no manejo de casos de MDR- TB ${ }^{37}$. Em estudo realizado no estado de São Paulo, Brasil, foram observados pacientes acometidos com MDR-TB de 2000 a 2012. Houve 1.097 notificações para essa forma de TB nesse período, sendo $70 \%$ dos pacientes homens, com idade média de 38 anos. Também foi registrada uma queda na mortalidade por MDR-TB, de $30 \%$ entre 2000 e 2003 para $8 \%$ entre 2009 e 2012 e uma alta na taxa de cura dos pacientes, de $53 \%$ entre 2000 e 2003 para $68 \%$ entre 2009 e $2012^{28}$.

Outro estudo Brasileiro, no estado de São Paulo, incluiu 313 pacientes diagnosticados microbiologicamente no Instituto Adolfo Lutz como MDR-TB. As proporções de pacientes XDR TB e pré XDR-TB entre os MDR-TB foram 10,2\% (32/313) e 19,2\% (60/313), respectivamente. As taxas de TB-XDR foram de 6,6\% em 2011, 10,1\% em 2012 e 13,9\% em 2013. Considerando os 248 isolados com resultados para todos os medicamentos de primeira e segunda linha testados, $2,8 \%(7 / 248)$ foram resistentes a todas as drogas. Todos esses pacientes foram previamente tratados para TB. A maior parte da transmissão de XDR-TB ocorreu em domicílios ou entre vizinhos, mas uma transmissão ocupacional também foi observada. A média de idade foi 39-40 anos e comorbidades e comportamentos de risco foram obtidos para os 32 pacientes com XDR- TB. Os mais frequentes foram co-infecção pelo HIV e diabetes mellitus. Entre os 32 pacientes com TB XDR, $14(43,7 \%)$ tinham MDR-TB e três $(9,4 \%)$ tinham TB-XDR primária ${ }^{38}$.
Em Porto Príncipe, capital do Haiti, foi realizado um estudo para determinar a prevalência de MDR-TB por meio de testes moleculares. Foram testados 1.006 pacientes com suspeita de TB, sendo 906 confirmados. Em 27 isolados de MTB foram detectadas mutações ou deleções no gene rpoB, tendo $26(2,9 \%)$ amostras confirmadas para a forma MDR-TB. Não foram observadas associações estatisticamente significantes entre idade, gênero ou soropositividade para HIV e TB resistente ${ }^{39}$.

\section{Mediterrâneo Oriental}

No Mediterrâneo Oriental, que inclui países do Oriente Médio e norte da África, foram notificados 527.693 casos de TB em 2016, sendo 7,96\% do total mundial. Quanto à MDR/RR-TB e a XDR-TB, foram 4.713 e 152 casos, respectivamente. Essa região possui o melhor índice de sucesso no tratamento entre as estudadas (Tabela 2). Entre os 30 países com maior número de pacientes com MDR/RR-TB, o Paquistão possui a melhor taxa de sucesso terapêutico da região, com $65 \%{ }^{1,24}$.

Em Israel, um estudo demonstrou os maiores fatores de risco da MDR-TB nesse país. Foram observados 207 pacientes com MDR-TB, sendo o maior número de pacientes acometidos eram homens, com idade entre 30-59 anos, imigrantes principalmente da antiga União Soviética, onde provavelmente contraíram o bacilo, porque estavam em Israel por mais de 2 anos. A forma da TB era pulmonar, com baciloscopia positiva e portador do vírus da imunodeficiência humana. Também foi analisado o êxito do tratamento. Cerca de $71 \%$ dos pacientes com MDR-TB tiveram o tratamento bem sucedidos, enquanto que 19,8\% morreram. Foram diagnosticados 12 pacientes com XDR-TB, sendo que sete $(58,4 \%)$ obtiveram cura e cinco $(41,6 \%)$ morreram ${ }^{29}$.

Em revisão sistemática sobre a TB resistente no Irã, foi observado que a MDR-TB estava presente em $5,1 \%$ dos casos novos de TB (228) e em 33,7\% dos casos de reinício de tratamento (335). O Irã faz fronteira com países com alta taxa de MDR-TB, o que contribui para a transmissão dessa forma da doença e o aumento da resistência do bacilo. A incidência em novos casos da MDR-TB demonstra a ocorrência da transmissão entre a população em geral e também o uso inadequado da medicação anti-TB, que leva ao surgimento da resistência. A prevalência em casos de pacientes já tratados é ainda mais preocupante. A resistência à estreptomicina 692 (19\%) foi a maior encontrada entre os casos novos e à isoniazida (47\%) foi a maior entre os casos já previamente tratados. Tais dados são importantes para a definição da 
estratégia de controle da TB para que os esquemas de tratamento sejam mais eficientes ${ }^{30}$.

Em estudo realizado com pacientes turcos, foram analisados 387 pacientes com TB pulmonar ativa num período de 5 anos (2000-2004) em um hospital para cirurgias peitorais e torácicas. MDR-TB foi encontrada em $2,16 \%$ dos novos casos de TB (5), $11,3 \%$ em casos de reinício de tratamento (6) e em $92,3 \%$ dos casos crônicos (12). Já em revisão feita com estudos na Arábia Saudita, publicados entre 1979 e 2013, observou o padrão MDR-TB em 6,7\% dos indivíduos testados, sendo $16 \%$ em indivíduos previamente tratados e $1,3 \%$ em casos novos ${ }^{24,40,45}$.

\section{Continente Europeu}

O continente europeu é um caso diferente devido à grande quantidade de pacientes com tuberculose, infectados com bacilos resistentes. Essa região possui $3,93 \%$ dos casos mundiais de TB, com 260.434 notificações. Quanto às formas resistentes, a Europa notificou 49.442 casos de MDR/RR-TB e 3.114 casos de XDR-TB, ambos os números são maiores em casos absolutos em todo o mundo. Quanto à taxa de sucesso do tratamento para a MDR/RR-TB, $59 \%$ dos pacientes obtiveram êxito. Já para a XDR-TB, a taxa de sucesso foi de $27 \%$. Nessa região, é digno de menção o Cazaquistão, cuja taxa de sucesso de tratamento é de $76 \%^{1,24}$.

Um estudo foi realizado com dados de 23 centros de 16 países europeus com diferentes taxas de incidências de TB e detectou 380 pacientes acometidos com cepas MDR-TB entre os anos de 2010 e 2011. Dentre estes, foi predominante o gênero masculino, com média de idade de 36 anos, variando entre 27 e 47, sendo 50,5\% de tabagistas. Estrangeiros contabilizaram 94 pacientes, sendo que $60(64 \%)$ eram de países da região européia da OMS, $17(18 \%)$ da Rússia, 18 (19\%) do sudeste asiático, $11(12 \%)$ da África Subsaariana, 1 (1\%) do norte da África e 4 (4\%) da América do Sul. A infecção por HIV entre os pacientes com MDR-TB foi de $6,6 \%$ e os portadores de diabetes mellitus contabilizavam $4,2 \%{ }^{41}$.

Um estudo realizado entre os anos de 2010 e 2011 com portadores de MDR-TB radicados no Reino Unido associou a TB resistente à região de origem dos pacientes. Dos 179 pacientes participantes do estudo, $38(21 \%)$ eram originados do leste europeu, entre eles 18 da Lituânia, 8 da Romênia, 5 da Letônia, 2 da Ucrânia e da Rússia e 1 da Geórgia, do Cazaquistão e da Polônia. Quanto as outras regiões, 99 (55\%) pacientes eram da Ásia, 28 (16\%) da África e $14(8 \%)$ do próprio Reino Unido. Houve também uma prevalência de 18\% (7 em 38) de XDR-TB entre os pacientes vindos do leste europeu. Estes dados alinham-se com os achados nos anos 2009 e 2010, quando os maiores índices de ocorrência de MDR-TB foram na Rússia e nos Países Bálticos (Lituânia, Letônia e Estônia) ${ }^{42}$.

Outro estudo dedicado a relatar a situação da TB resistente na Lituânia, país da antiga União Soviética, observou que, em 2013, enquanto a taxa de TB resistente em países da União Européia era de 10,7\%, na Lituânia era de $34,8 \%$. Tal fato não é novo: em 2006, essa taxa era de $29,2 \%$. Havia 271 pacientes com MDR-TB, dentre esses $59 \mathrm{com}$ XDR-TB. Entre os acometidos de MDR-TB, eram mais comuns homens, desempregados, com formação básica ou ensino médio completos, vivendo em ambientes urbanos e com frequente consumo de bebidas alcoólicas. O êxito no tratamento também é baixo nesse país, sendo de $35,1 \%$ em 2013 , menor que seus vizinhos Letônia e Estônia, com $53,7 \%$ e $50,0 \%$, respectivamente ${ }^{31}$.

\section{Sudeste Asiático}

O sudeste da Ásia possui o maior número de casos totais de TB notificados no ano de 2016 entre as regiões estudadas, com 2.898 .482 casos, representando $43,75 \%$ dos casos mundiais. Essa região fica em segundo lugar no número de casos de MDR/RR-TB (Tabela 3). Obtiveram sucesso no tratamento para a MDR/RR-TB 50\% dos pacientes, enquanto que para a XDR-TB, a taxa de sucesso foi de $29 \%$. Vale destacar a República Popular Democrática da Coréia e Myanmar, cujas taxas de sucesso no tratamento foram as maiores entre 30 países com alto índice de TB resistente, com $91 \%$ e $80 \%$, respectivamente ${ }^{1,24}$.

$\mathrm{Na}$ Índia, estima-se que a prevalência de MDR-TB entre novos casos de TB seja de 2,2\% e entre pacientes anteriormente tratados, de $15 \%$. Em estudo feito no distrito de Surat, usou questionários para tentar determinar os maiores fatores de risco para o surgimento da MDR-TB, que, na Índia, tem índice de 2,2\% em casos novos e15\% em casos já previamente tratados.

Foram encontradas relações estatisticamente significantes entre a MDR-TB e o sexo masculino, ter somente educação básica, ser migrante, estar abaixo da linha de pobreza, trabalhar em indústria, ser etilista e a coinfecção com HIV. Outro estudo realizado na Índia, em Nagpur, observou a grande ocorrência de MDR-TB em casos de recidiva da doença e em casos de falha terapêutica. Entre os 249 pacientes com MDR-TB incluídos no estudo, 117 (47\%) haviam sofrido recidiva e 96 (39\%) eram casos de falha terapêutica ${ }^{32-34}$.

Também na Índia foi descrita outra forma resistente de TB, em que quatro pacientes apresentaram cepas resistentes a todos os medicamentos de primeira 
e segunda linha, que poderiam ser considerados "TB totalmente resistente a medicamentos", mas o termo "tuberculose totalmente resistente aos medicamentos" é controverso porque ainda não existe uma definição oficial além do XDR-TB ${ }^{43}$. Tal forma surgiu de um tratamento inadequado para MDR-TB, com uso de fármacos de segunda linha de forma errônea, sem supervisão e usados individualmente, feita com prescrição de profissionais da rede privada ${ }^{44}$.

\section{Pacífico Ocidental}

A região do Pacífico ocidental possui $21,14 \%$ dos casos totais de TB do planeta, sendo 1.400.638 dos casos notificados em 2016. Entre os casos de MDR/RR-TB e XDR-TB, foram notificados 21.152 e 618 casos, respectivamente. $O$ sucesso terapêutico nessa região foi de $52 \%$ para a MDR/RR-TB, e para a XDR-TB, a taxa de sucesso foi de $40 \%$. É digno de menção que o Vietnã possui a maior taxa de sucesso no tratamento entre os países da região na lista dos 30 com o maior número de casos de TB resistente, com $75 \%$ dos casos obtendo sucesso no tratamento ${ }^{1,24}$.

Estudo realizado em Xangai, China, entre 2009 e 2012 procurou determinar os fatores de risco associados à MDR-TB. Foram acompanhados 269 pacientes já diagnosticados sendo 199 (74\%) homens, $133(49,4 \%)$ migrantes de outras regiões da China, $115(42,8 \%)$ já haviam sido tratados previamente para TB e $84 \%$ tinham baciloscopia positiva. Quanto ao sucesso do tratamento, este era pior para homens acima dos 45 anos, residentes de Xangai (não migrantes), que já tinham passado por tratamento para TB e que possuíam baciloscopia positiva. Outro fato que pareceu piorar as chances de êxito no tratamento foi a distância da casa do paciente até o hospital em que o acompanhamento da TB era realizado; quanto mais longe, piores as chances $^{35}$.

Na República da Coréia, outro estudo analisou retrospectivamente pacientes confirmados com TB entre 2010 e 2014 em sete hospitais universitários. Dos 5.599 isolados, foi diagnosticado MDR-TB em $378(6,8 \%)$. Diferentemente dos demais estudos, nesse foi observado que a maioria dos pacientes com MDR-TB nunca haviam sido tratados, contabilizando $216(57,1 \%)$, demonstrando que a taxa de transmissão é alta. Já haviam sido tratados com fármacos de primeira linha 125 pacientes $(33,1 \%)$ e $37(9,8 \%)$ com fármacos de segunda linha. Eram homens 242 (64\%), com idade média de 47,8 anos. Foram observadas também resistências adicionais a MDR-TB, tais como resistência ao etambutol em $63,8 \%$ dos pacientes, à pirazinamida em $35,7 \%$, ao menos um injetável de segunda linha em 19,3\% e ao menos um fluoroquinolonas em $26,2 \%$. AXDR-TB foi encontrada em 12,4\% dos indivíduos. Os altos níveis de resistência encontrados denotam o grande desafio de construir esquemas terapêuticos de sucesso ${ }^{36}$.

\section{Resistência Global}

Dados mais recentes da OMS, de 2016, mostram que 6.624.523 casos de TB foram notificados mundialmente, dos quais 153.119 casos tiveram confirmação laboratorial de MDR-TB entre casos os notificados de TB pulmonar, sendo $4,1 \%$ de novos casos de resistência e $19 \%$ de casos previamente tratados, com taxa de sucesso de $54 \%{ }^{24}$.

Dados de 2015 mostram 250.000 mortes provenientes da MDR-TB. Pelo menos 35 países da África e da Ásia introduziram tratamentos de menor duração, com taxas melhores de sucesso. Cerca de $9,5 \%$ dos casos de MDR-TB possuem resistência adicional, tornando-se XDR-TB, totalizando 8.014 pacientes em $2016^{1}$.

Até hoje, 117 países notificaram pelo menos um caso de XDR-TB, que possui taxa de sucesso no tratamento de $30 \%$. Em 68 países e territórios, 8.511 pacientes com XDR-TB, iniciaram tratamento em 2016, gerando um aumento de $17 \%$ em relação a 2015. No entanto, em 29 desses países, o número de casos de XDR-TB notificados foi maior que o número de pacientes que iniciaram tratamento. Numa tentativa de melhorar as chances dos pacientes, 89 países e territórios passaram a utilizar bedaquilina no tratamento para MDR/XDR-TB, enquanto outros 54 iniciaram o uso de delamanida até junho de $2017^{1,6,24}$.

Na tabela 3 estão distribuídos os casos confirmados MDR/RR-TB (TB resistente à rifampicina) e XDR-TB em diferentes regiões do mundo e a frequência de sucesso do tratamento, além dos principais dados epidemiológicos encontrados associados à resistência.

\section{CONSIDERAÇÕES FINAIS}

Destacamos nessa revisão facetas importantes sobre a MDR-TB e XDR-TB, tais como a distribuição de casos e as taxas de sucesso do tratamento nos diversos continentes.

Foram elencadas as principais características epidemiológicas em diversos estudos disponíveis. Os mais citados foram: gênero masculino, HIV+, ser imigrante ou migrante, falha terapêutica, etilismo e baciloscopia positiva, respectivamente. Outros pontos menos citados foram: casos recorrentes de TB, tabagismo, uso inadequado de medicamento, diabetes mellitus, estar em ambientes urbanos, estar abaixo da linha da pobreza e reinicio do tratamento. A média de idade geral variou principalmente de 30 a 59 anos. 
O número de casos resistentes foi maior no continente europeu e menor no americano. A taxa de sucesso em relação ao tratamento para MDR/RR-TB foi menor no continente americano $(46 \%)$ e maior no mediterrâneo Oriental com $65 \%$. Já em relação à XDR-TB a frequência de sucesso do tratamento foram menores na África e Europa (27\%) e maior nas Américas (48\%).

Diversas razões foram atribuídas para justificar a diferença nas taxas do sucesso do tratamento nos vários continentes, tais como a alta concentração populacional, a desorganização dos serviços de saúde em campos de refugiados, as diferentes realidades epidemiológicas nos locais abordados, pacientes infectados com bacilos com diferentes perfis de resistência que dificultam o tratamento, a distância da unidade de tratamento e o abandono do tratamento.

Globalmente, 4,1\% dos casos resistentes foram casos novos de resistência e 19\% de casos previamente tratados.

Merece atenção a ocorrência de quatro casos que apresentaram cepas resistentes a todos os fármacos testados em laboratório no sudeste asiático devido a um tratamento inadequado.

Em alguns locais, foi registrada uma queda na mortalidade por MDR-TB, e uma alta na taxa de cura dos pacientes, e em contrapartida em outros há subnotificação dos casos.
Há ainda uma diferença entre o número de pacientes notificados e tratados. Em 29 desses países, o número de casos de XDR-TB notificados foi maior que o número de pacientes que iniciaram tratamento.

Verificamos que existem ainda lacunas de conhecimento sobre a real magnitude da situação no Brasil e em outras localidades.

É necessário, ainda, investigar melhor os genes de resistência e o grande desafio atual é a elaboração de esquemas terapêuticos eficazes para uma contribuição mais efetiva ao problema global da resistência. Estudos científicos podem contribuir para melhor conhecimento da magnitude da resistência em seus diferentes aspectos.

Por fim, esta revisão, utilizando os estudos publicados nas principais bases científicas disponíveis possui um objetivo que viabilizou sumarizar os estudos incluídos sobre o tema abordado em diferentes contextos, e sua divulgação pode ser útil para a implementação de medidas voltadas ao controle da resistência às drogas antituberculose.

\section{Agradecimentos}

Os autores agradecem ao Programa de Aprimoramento Profissional do Instituto Adolfo Lutz (PAP/IAL).

\section{Conflitos de Interesse}

Os autores declaram não ter conflitos de interesse.

\section{REFERÊNCIAS}

1. World Health Organization (WHO) Global Tuberculosis Report 2017. Geneva: WHO; 2017.

2. World Health Organization (WHO). Tuberculosis. WHO; 2017. [cited 2017 Nov 25]. Available from: http://www. who.int/mediacentre/factsheets/fs104/ en/.

3. Brasil. Ministério da Saúde. Manual de Recomendações para o Controle da Tuberculose no Brasil. 1. ed. Brasília: Ministério da Saúde; 2011.

4. Brasil. Ministério da Saúde. Secretaria de Vigilância em Saúde. Departamento de Vigilância Epidemiológica. Programa Nacional de Controle da Tuberculose. Nota técnica sobre as mudanças no tratamento da tuberculose no Brasil para adultos e adolescentes. Brasília: Ministério da Saúde; 2012.
5. Lynch JB. Multidrug-resistant Tuberculosis. Med Clin North Am. 2013;97(4):553-79. http://dx.doi. org/10.1016/j.mcna.2013.03.012. PMid:23809714.

6. Dheda K, Gumbo T, Maartens G, Dooley K, McNerney R, Murray $M$, et al. The epidemiology, pathogenesis, transmission, diagnosis, and management of multidrug-resistant, extensively drugresistant, and incurable tuberculosis. Lancet Respir Med. 2017;5(4):291360. http://dx.doi.org/10.1016/S2213 2600(17)30079-6. PMid:28344011.

7. Seung K, Keshavjee S, Rich M. Multidrug-resistant tuberculosis and extensively drug-resistant tuberculosis. Cold Spring Harb Perspect Med. 2015;5(9):1-20. http:// dx.doi.org/10.1101/cshperspect. a017863
8. Teixeira GM. XDR-TB - uma grave e emergente ameaça à saúde pública. Rev Bras Pneumol Sanit. 2007;15(1):3-6.

9. Slim-Saidi L, Mehiri-Zeghal E, Ghariani A, Tritar F. Nouvelles méthodes de diagnostic dela tuberculose. Rev Pneumol Clin. 2015;71(2-3):110-21. http://dx.doi. org/10.1016/j.pneumo.2015.02.002. PMid:25754128.

10. Keshavjee S, Farmer P. Tuberculosis, drug resistance, and the history of modern medicine. Engl J Med. 2012;367(10):931-6. http://dx.doi. org/10.1056/NEJMra1205429. PMid:22931261.

11. World Health Organization (WHO). What is multidrug-resistant tuberculosis (MDR-TB) and how do we control it?. WHO; 2017. [cited 2017 Nov 29]. Available from: http://www. who.int/features/qa/79/en/ 
12. Dharmadhikari AS, Mphahlele M, Venter K, Stoltz A, Mathebula R, Masotla T, et al. Rapid impact of effective treatment on transmission of multidrug-resistant tuberculosis. Int $\mathrm{J}$ Tuberc Lung Dis. 2014;18(9):1019-25. http://dx.doi.org/10.5588/ijtld.13.0834. PMid:25189547.

13. Palomino JC, Vandamme P, Martin A. Classical and new assays for detecting drug resistance in tuberculosis. Biomark Med. 2014;8(9):1105-14. http:// dx.doi.org/10.2217/bmm.14.73 PMid:25402580.

14. Mani $V$, Wang $S$, Inci F, De Libero G, Singhal A, Demirci U. Emerging technologies for monitoring drugresistant tuberculosis at the pointof-care. Adv Drug Deliv Rev. 2014;78:105-17. http://dx.doi. org/10.1016/j.addr.2014.05.015. PMid:24882226.

15. World Health Organization (WHO). Treatment guidelines for drug-resistant tuberculosis. 2016 update. October 2016 revision. Geneva: WHO; 2016.

16. Günther G. Multidrug-resistant and extensively drug-resistant tuberculosis: a review of current concepts and future challenges. Clin Med (Lond). 2014;14(3):27985. http://dx.doi.org/10.7861/ clinmedicine.14-3-279. PMid:24889573.

17. Goldman RC, Plumley K, Laughon B. The evolution of Extensively Drug Resistant Tuberculosis (XDR-TB): history, status and issues for global control. Infect Disord Drug Targets. 2007;7(2):73-91. http://dx.doi. org/10.2174/187152607781001844. PMid:17970220.

18. Dheda K, Gumbo T, Gandhi N, Murray M, Theron G, Udwadia Z, et al. Global control of tuberculosis: from extensively drug-resistant to untreatable tuberculosis. Lancet Respir Med. 2014;2(4):321-38. http://dx.doi.org/10.1016/S22132600(14)70031-1. PMid:24717628.

19. Prim RI. Caracterização molecular de estirpes de Mycobacterium tuberculosis resistentes à isoniazida e/ou rifampicina isoladas de amostras clínicas do estado de Santa Catarina [dissertation]. Florianópolis (SC): Universidade Federal de Santa Cataria; 2014.
20. Santos DP, Souza DV, Rodrigues $S$, Avelas KES. Resistência aos fármacos de primeira escolha utilizados no tratamento da tuberculose pulmonar por Mycobacterium tuberculosis. Revista de Saúde. 2012;4(1):13-25.

21. Zhang $Y$, Yew WW. Mechanisms of drug resistance in Mycobacterium tuberculosis. Int J Tuberc Lung Dis. 2009;13(11):1320-30. PMid:19861002.

22. Zhang Y, Yew W. Mechanisms of drug resistance in Mycobacterium tuberculosis: update 2015. Int J Tuberc Lung Dis. 2015;19(11):127689. http://dx.doi.org/10.5588/ ijtld.15.0389. PMid:26467578.

23. Almeida Da Silva PE, Palomino JC. Molecular basis and mechanisms of drug resistance in Mycobacterium tuberculosis: classical and new drugs. J Antimicrob Chemother. 2011;66(7):1417-30. http:// dx.doi.org/10.1093/jac/dkr173. PMid:21558086.

24. World Health Organization (WHO). Global Tuberculosis Report 2017. Annex 3: Regional and global profiles. Geneva: WHO; 2017.

25. Kidenya BR, Webster L, Behan S, Kabangila R, Peck R, Mshana S, et al. Epidemiology and genetic diversity of multidrug-resistant tuberculosis in East Africa. Tuberculosis (Edinb). 2014;94(1):1-7. http://dx.doi. org/10.1016/j.tube.2013.08.009. PMid:24215798.

26. Noeske J, Foe J, Kuaban C. Cameroon's MDR-TB treatment programme jeopardised by crossborder migration. Eur Respir J. 2016;47(2):684-6. http://dx.doi. org/10.1183/13993003.01324-2015. PMid:26828058.

27. Fregona G, Cosme LB, Moreira CMM, Bussular JL, Dettoni VV, Dalcolmo MP, et al. Risk factors associated with multidrug-resistant tuberculosis in Espírito Santo, Brazil. Rev Saude Publica. 2017;51(41):111. http://dx.doi.org/10.1590/ s1518-8787.2017051006688. PMid:28489185.

28. Bollela VR, Puga FG, Moya MJ, Andrea M, Oliveira MLV. A DecadeTrend of Multidrug Resistant Tuberculosis in São Paulo State, Brazil. Rev Inst Med Trop São Paulo. 2016;58(0):77. http://dx.doi. org/10.1590/S1678-9946201658077. PMid:27828618.
29. Mor Z, Goldblatt D, Kaidar-Shwartz H, Cedar N, Rorman E, Chemtob $D$. Drug-resistant tuberculosis in Israel: risk factors and treatment outcomes. Int J Tuberc Lung Dis. 2014;18(10):1195-201. http:// dx.doi.org/10.5588/ijtld.14.0192. PMid:25216833.

30. Nasiri MJ, Dabiri H, Darban-Sarokhalil D, Rezadehbashi M, Zamani S. Prevalence of drug- resistant tuberculosis in Iran: Systematic review and meta-analysis. Am J Infect Control. 2014;42(11):1212-8. http:// dx.doi.org/10.1016/j.ajic.2014.07.017. PMid:25242634.

31. Musteikienè G, Miliauskas $S$, Sakalauskas R, Vitkauskienè A, Žemaitis M. Multidrug-resistant tuberculosis in Lithuania - Still a long way ahead. Medicina (Kaunas). 2016;52(2):69-78. http://dx.doi. org/10.1016/j.medici.2016.02.002. PMid:27170479.

32. Prasad R, Gupta N, Singh M. Multidrug resistant tuberculosis: trends and control. Indian J Chest Dis Allied Sci. 2014;56(4):237-46. PMid:25962197.

33. Munje R, Deshmukh R, Tumane K. Multidrug-resistant TB among previously treated TB cases: A retrospective study in Nagpur, India. Indian J Tuberc. 2015;62(4):20710. http://dx.doi.org/10.1016/j. ijtb.2015.11.002. PMid:26970460.

34. Yadav SK, Damor R, Kantharia SL, Tiwari M. Risk Factors of Multi Drug Resistant Tuberculosis among TB Patients in Surat District, Gujarat, India: A Case Control Study. IOSR Journal of Dental and Medical Sciences. 2016;15(12):96-101.

35. Li D, Ge E, Shen X, Wei X. Risk Factors of Treatment Outcomes for Multi-drug Resistant Tuberculosis in Shanghai, 2009-2012. Procedia Environ Sci. 2016;36:12-9. http://dx.doi.org/10.1016/j. proenv.2016.09.003.

36. Mok JH, Kang B, Lee T, Lee H, Jang $\mathrm{H}$, Cho $\mathrm{Y}$, et al. Additional drug resistance patterns among multidrug-resistant tuberculosis patients in Korea: implications for regimen design. J Korean Med Sci. 2017;32(4):636-41. http://dx.doi. org/10.3346/jkms.2017.32.4.636. PMid:28244290. 
37. World Health Organization (WHO). Global tuberculosis report 2015. 20th ed. Geneva: WHO; 2015.

38. Gallo JF, Pinhata JMW, Simonsen V, Galesi VMN, Ferrazoli L, Oliveira RS. Prevalence, associated factors, outcomes and transmission of extensively drug-resistant tuberculosis among multidrug-resistant tuberculosis patients in São Paulo, Brazil: a cross-sectional study. Clin Microbiol Infect. 2017;24(8):889-95. https://doi. org/10.1016/j.cmi.2017.11.01.

39. Ocheretina O, Morose W, Gauthier M, Joseph P, D'Meza $\mathrm{R}$, Escuyer VE, et al. Multidrugresistant tuberculosis in Portau-Prince, Haiti. Rev Panam Salud Publica. 2012;31(3):2214. http://dx.doi.org/10.1590/ S1020-49892012000300006. PMid:22569696.
40. Al-Tawfiq JA, Hinedi K, Memish ZA. Systematic review of the prevalence of Mycobacterium tuberculosis resistance in Saudi Arabia. $J$ Chemother. 2015;27(6):378-82. http://dx.doi.org/10.1179/197394781 5Y.0000000058. PMid:26179987.

41. Günther $G$, van Leth F, Alexandru $\mathrm{S}$, Altet N, Avsar K, Bang D, et al. Multidrug-Resistant Tuberculosis in Europe, 2010-2011. Emerg Infect Dis. 2015;21(3):409-16. http:// dx.doi.org/10.3201/eid2103.141343. PMid:25693485.

42. Gonzalo X, Hutchison DCS, Drobniewski FA, Pimkina E, Davidaviciene E. Multidrug-resistant tuberculosis in the United Kingdom and Lithuania. Int $J$ Tuberc Lung Dis. 2014;18(6):663-5. http:// dx.doi.org/10.5588/ijtld.13.0342. PMid:24903935.
43. Stop TB Partnership. United to End TB Every Word Counts: Suggested language and usage for tuberculosis comunications. Geneva: Stop TB Partnership Secretariat; 2015. [cited 2018 Mar 15]. Available from: http:// www.stoptb.org/webadmin/cms/docs/ Every\%20Word\%20Counts\%20 TB\%20Language\%20Guide.pdf

44. Udwadia ZF, Amale RA, Ajbani KK, Rodrigues C. Totally DrugResistant Tuberculosis in India. Clin Infect Dis. 2012;54(4):579-81. http://dx.doi.org/10.1093/cid/cir889. PMid:22190562.

45. Komurcuoglu B, Senol G, Balci G, Yalnız E, Ozden E. Drug resistance in pulmonary tuberculosis in new and previously treated cases: Experience from Turkey. J Infect Public Health. 2013;6(4):276-82. http:// dx.doi. org/10.1016/j.jiph.2013.02.005. PMid:23806702.

Recebido: 04 maio, 2018 Aceito: 16 ago, 2018 